\title{
American Indian/Alaska Native community infrastructure limitations amid the COVID-19 threat
}

\author{
Christine Samuel-Nakamura*1, Felicia Schanche Hodge ${ }^{2}$ \\ ${ }^{1}$ School of Nursing, University of California Los Angeles, Los Angeles, USA \\ ${ }^{2}$ School of Nursing and Fielding School of Public Health, University of California Los Angeles, Los Angeles, USA
}

Received: December 18, 2020

DOI: $10.5430 /$ jnep.v11n8p62
Accepted: April 8, 2021

URL: https://doi.org/10.5430/jnep.v11n8p62

\begin{abstract}
Objective: The recent SARS-CoV-2 (COVID-19) pandemic that is spreading throughout the nation is a particular threat to American Indian and Alaska Native (AI/AN) communities. The use of recommended methods to prevent or mitigate the spread of the virus, such as hand washing, social distancing, masks, contact tracing and community education is highly problematic at many of these sites. The objective of this paper is to identify and examine structural or cultural barriers to implementing COVID-19 recommendations on select reservation sites.

Methods: A qualitative approach that collected and analyzed data from existing sources including newsletter articles, relevant policies and other published reports was instituted in the Spring of 2020. The Centers for Disease Control and Prevention (CDC) policies regarding COVID-19 recommendations to halt the spread of the virus were selected as the standard for COVID-19 prevention, surveillance and mitigation. News articles between March 1, 2020 and December 1, 2020 were identified using various search engines and tribal websites. Information from news resources, including literature reviews, newsletter articles, social media reports, and tribal policy announcements, were gathered and reviewed. Two U.S. southwestern communities are used as examples for the review.

Results: Data collected from various sources paint a picture of American Indian communities that lack adequate community infrastructures, and have problems of residential isolation, close living quarters, and contaminated and scarce water supplies. Unsafe or limited water restricts handwashing. Limited informational tools, such as telephone, internet, computer and newsletters, restricted adequate notification of the novel coronavirus to American Indian reservation communities. Often, the lack of a physical home address can create barriers to healthcare accessibility and surveillance, as it limits the identification and access to households. In addition, many traditional cultures of AI/ANs emphasize the interrelatedness of all in nature and thus require an ecological approach to health education and preventive measures, identified as a limitation for COVID-19 surveillance and mitigation.

Conclusions: AI/AN communities face a serious threat of contracting COVID-19. Four key infrastructure limitations to effective COVID-19 prevention, surveillance and mitigation were identified: limited access to safe water, deficient telecommunication networks (telephone, internet, and television), housing isolation and shortages, and inadequate medical services - are experienced by many AI/AN communities. Although there are 574 federally recognized tribes in the United States, the two identified in this study subscribe to an ecological approach to health education and preventive measures in that they believe in the interrelatedness of all things in nature. Surveillance questions may be misunderstood or seem invasive and prevention measures (masks, social distancing, and handwashing) may seem to be extreme measures to groups so close to the environment. Together, these present serious barriers to prevention and mitigation of the COVID-19 virus in this underserved population.
\end{abstract}

Key Words: American Indian, Alaska Native, COVID-19, Infrastructure, Contamination, Water, Telecommunication, Housing, Culture, Healthcare

*Correspondence: Christine Samuel-Nakamura; Email: csamnak@ucla.edu; Address: School of Nursing, University of California Los Angeles, Los Angeles, USA. 


\section{INTRODUCTION}

The recent novel SARS-CoV-2 coronavirus 2019 (COVID19) pandemic has affected racial/ethnic populations disproportionately higher than the general population. African American and Hispanic/Latino groups report COVID-19 mortality rates of 73-184 per 100,000 for African Americans and 36-187/100,000 for Hispanic/Latinos in comparison to 22$93 / 100,000$ for the general population. ${ }^{[1]}$ The pandemic is a particular threat to American Indian and Alaska Native (AI/AN) communities as the Centers for Disease Control and Prevention in the Morbidity and Mortality Weekly Report indicates that AI/ANs are 3.5 times more likely to contract COVID-19 than their White counterparts. ${ }^{[2]}$ Further, AI/AN communities tended to have persistent disparities (preventative measures and testing access, safe work and education, vaccination eligibility) for the duration of the pandemic compared to their counterparts. ${ }^{[3]}$

The use of recommended methods to prevent or mitigate the spread of the COVID-19 virus, such as hand washing, social distancing, masks and education is highly problematic in many $\mathrm{AI} / \mathrm{AN}$ communities. Communication and sociocultural gaps and infrastructure shortfalls create challenges for healthcare providers, first responders and tribal leaders. These shortfalls are of significant concern, contributing to serious and longstanding disparities, inequities, vulnerabilities, and potential threats to the lives of an Indigenous population. This paper reports on the flow of information on the COVID-19 virus to and among tribal groups as well as the infrastructure problems experienced in these communities, many of which have contributed to the spread and negative impact of the COVID-19 virus.

\section{Methods}

The official policy directives for COVID-19 surveillance, mitigation and treatment originate within the $\mathrm{CDC}$ and are disseminated largely by social media. Centers for Disease Control and Prevention policies regarding COVID-19 surveillance and mitigation were identified and updated whenever revisions were issued. News articles published between March 1, 2020 and December 1, 2020, coupled with literature searches using PubMed and Google search engines and tribal websites provided project data for analysis. Information from tribal news sources, including community flyers, social media reports, and tribal policy announcements, were gathered and reviewed. Selection criteria included terms that mentioned American Indian, Alaska Native, tribe, and COVID-19. About $1.7 \%$ of the U.S. population (5.2 million) self-identify as AI/AN: ${ }^{[4]} 54 \%$ of this population resides in rural areas or near small towns. ${ }^{[5]}$ Two southwestern AI communities were highlighted in this report to illustrate the

Published by Sciedu Press descriptions of the type and extent of the limitations discussed.

\section{RESULTS}

Poor reservation infrastructures, sociocultural factors, problems of residential isolation, close living quarters, and contaminated and scarce water sources has led to poor COVID19 surveillance and mediation. Sparse informational tools, such as telephone, internet, and newsletters limited notification of the coronavirus to AI/AN communities. Initially, little was published about COVID-19 incidence in or near AI/AN communities. News reporting regarding the pandemic arising from the Navajo Nation ${ }^{[6-9]}$ in March and April, 2020, highlighted the unique impact of this virus on reservation sites, thus alerting other tribes of the spreading pandemic as well as the problematic nature of prevention, management and mitigation of COVID-19. These problems include four key infrastructure limitations to telecommunication, housing, water, and limited medical care experienced by many $\mathrm{AI} / \mathrm{AN}$ communities when conflated with cultural factors contribute to serious vulnerability and potential threats to mitigation of the COVID-19 virus.

\subsection{Infrastructure limitations}

The recent novel COVID-19 pandemic that is spreading throughout the nation has spotlighted the infrastructure limitations of many tribal communities. Due to infrastructure shortfalls, many reservations may be unable to participate in recommended COVID-19 prevention and control measures such as handwashing, social distancing, and mask wearing. Over the years, anthropogenic environmental contaminants have poisoned water supplies limiting access to safe water and recommended handwashing. Problems of isolation and close living quarters makes social distancing problematic. To develop and implement a program of COVID-19 education and infectious disease mitigation, the traditional AI/AN belief that all in nature are interlinked needs to be understood and considered by healthcare providers, educators, planners, and researchers. Many traditional cultures of AI/ANs emphasize the interrelatedness of all in nature, thus ecological approaches to mitigating the spread of the virus may require more levels of collaboration. In addition, late notification of the coronavirus threat limited surveillance, particularly in a population that values privacy, independence, and freedom of movement. Each of these are of significant concern and together, they amount to serious vulnerability to the health of an Indigenous population.

\subsubsection{Telecommunication}

An important facet of pandemic surveillance and mitigation is the ability to notify individuals and communities about the 
threat of rapidly spreading diseases. Outdated, broken and unreliable telecommunication networks are not uncommon on reservations. Limited service networks are also aggravated by inclement weather conditions, such as snowstorms and excessive rainfall. When the COVID-19 pandemic was first announced, infrastructure limitations or absence of reservation telecommunication systems was soon recognized as the news of the novel virus was slow to reach these communities.

Many isolated reservations rely on radio stations, community or town hall meetings, informational flyers to communicate news, or notices of events for dissemination in their community. Access to the internet, and in some rural areas telephone access, is intermittent or non-existent. The communication venue for COVID-19 began in early March 2020 with national news media coverage for the general population followed by news reports from national AI/AN organizations announcing the new pandemic threat. ${ }^{[10]}$ Initially announced through local tribal meetings, the news of the pandemic soon started to spread. News from radio and newsletters provided dissemination of the majority of community-wide information. Flyers and bulletins notifying the patient population of the COVID-19 pandemic began to spread at tribal hospitals and clinics. ${ }^{[11]}$ Communicating through personal accounts and via local tribal radio stations, tribal councils took action and implemented policies to restrict work and to limit traffic on reservations essentially shutting down reservations. Curfew hours were restricted to limited daytime hours and in some cases, the reservation borders were closed to nonresidential traffic (Lees Y., personal communication, Mar.15, 2020). The newly enacted curfews were effective in mitigating a COVID surge. ${ }^{[12]}$ The impact of these measures across other reservations is yet to be determined.

As COVID-19 information was mobilized via funded programs, concerns arose among tribal healthcare providers regarding the infrastructure shortfalls that limit COVID-19 surveillance and outreach to targeted groups such as $\mathrm{AI} / \mathrm{AN}$ veterans, the elderly, rural groups, youth, and the disabled (Lees Y., personal communication, 2020 Mar 15). It became apparent that the procedures employed in larger metropolitan areas to identify, test, and educate their targeted population may not be effective in AI/AN communities, largely due to limited internet and telephone access and other communication outlets. According to one report based on the 2020 American Community Survey data, $13.8 \%$ of AI/ANs had no access to telephone services ${ }^{[13]}$ and internet access was available to less than $10 \%$ of the AI/AN population. ${ }^{[14]}$ For all tribal lands, 1.6 million people or $14 \%$ of the population lacks broadband and wireless advanced telecommunication services (1.3 million and 280,000 people in rural and urban areas, respectively). ${ }^{[15]}$

\subsubsection{Housing}

Historically and currently, housing needs have been a major concern in AI/AN communities on many reservations. The number of residential houses on reservations is inadequate and these limited houses are often situated in remote locations. For example, the Apache reservation, located in the state of Arizona, residents receive mail at the local post office rental box or via "general delivery" as the streets and houses may lack physical addresses. Emergency services and case tracing may be fraught with difficulties in locating community members. Limited housing, particularly in rural reservations, has led to multiple families and/or friends residing in small structures. "Couch surfing", defined as sleeping temporarily on a couch in a residence, is a common practice. These residential structures can house extended or multigenerational family members as well as cousins, friends, and others - perhaps including those visiting, relocating to and from urban areas.

The majority of reservations in the U.S. continue to face housing shortages. Approximately $\$ 33$ billion dollars would be needed to build 68,000 new and replacement homes to alleviate overcrowding in tribal communities. ${ }^{[16]}$ In the meantime, tribal communities continue with their practice of living in close quarters in a multi-generational household ${ }^{[17]}$ thus, the threat of virus transmission to family members, particularly to the elderly and vulnerable, is severe. Social distancing under these circumstances is not tenable.

\subsubsection{Water}

Another aspect of infrastructure concerns relate to COVID19 handwashing recommendations. Plumbing and water infrastructure is often non-existent or inadequate to handle a growing population on reservations. In one report, $47 \%$ of American Indian homes were in need of sanitation repairs (wastewater and sanitation) whereas six percent possessed no adequate home sanitation or lacked adequate indoor plumbing. ${ }^{[18]}$ A recent NBC news article reported that approximately $30 \%$ of homes on the Navajo Nation do not have access to clean water due to lack of plumbing or contaminated water sources. "You're saying 20 seconds of wash your hands with water," a Diné physician in Arizona said, "We do not have plumbing. And that's how I grew up". ${ }^{[19]}$ The recommended washing of hands for 20 seconds with water (to mitigate COVID-19 contamination) competes with the need for drinking water.

Contamination of reservation lands and water supplies limits access to safe water. One percent of the general U.S. population lacks access to safe water, whereas a greater percentage (9\%) of AI/AN communities lack access to safe 
water sources. ${ }^{[20]}$ On the Navajo Nation, it is reported that $30 \%$ of the community consumes unsafe water that is intended for livestock only or has unregulated water sources for drinking purposes. ${ }^{[21]}$ Multiple studies have found elevated levels of metal(loid)s, such as arsenic, cadmium, lead, vanadium, manganese, and uranium on Diné lands, ${ }^{[22-28]}$ and in human drinking water sources in communities that rely on water for ingestion, cleaning, agriculture, animal husbandry, and cultural needs. ${ }^{[29]}$ Hard rock mining and its' toxicants are only one example, as environmental contamination may occur from other industries (i.e., gas, coal, oil). One report related that more than 160,000 abandoned hard rock mines exist on American Indian lands in the western U.S. ${ }^{[30]}$

Understanding the significance of water source and usage characterization of a community is important in determining health risks and outcomes; the Safe Drinking Water Act provides no funding or resources for private well surveillance or clean-up activities across the nation. ${ }^{[31]}$ In the U.S., there are over 44.5 million people who use private well water for everyday use. ${ }^{[32]}$ Due to this limitation, many communities are left without certainty in terms of access to clean water in rural or suburban areas including reservations and tribal areas (predominantly in water systems that serve less than 10,000 persons). ${ }^{[33]}$ According to the U.S. EPA, 91\% of the U.S. population utilizing regulated public water systems met all health standards, while only $88 \%$ of AI/AN water systems met all applicable health-based standards. ${ }^{[20,21]}$ Increased exposure and co-exposure to multiple environmental contaminants are major threats to accessing safe water in AI/AN communities. The extent of contamination from all water sources (particularly private wells and/or non-regulated sources) are not well characterized or studied in AI/AN communities and require examination of associated health outcomes pre-, intra-, and post-pandemic.

\subsubsection{Healthcare}

American Indians and Alaska Natives are among the most disadvantaged of groups in the U.S. A history of trauma pervades this group, as they have suffered attempts at genocide, mass death due to viruses and diseases, environmental contamination, and other more recent traumas that include health inequities and disparities in access to healthcare services. ${ }^{[34,35]}$ The COVID-19 pandemic that is spreading throughout the nation is of particular threat to AI/ANs. Problems of shortage in medical personnel and facilities along with communication and infrastructure shortfalls create challenges for healthcare providers, first responders and tribal leaders. These areas are of significant concern and they amount to serious and longstanding disparities, inequities, vulnerabilities and potential threats to the lives of an Indigenous population.

Published by Sciedu Press
There are 574 federally recognized AI/AN tribes and groups in the U.S. experiencing some common threads contributing to an inadequate infrastructure in areas of communication, basic living needs (telecommunication, housing, and water), and response to health threats that impact COVID-19 mitigation and surveillance. These community characteristics amount to high risk factors and multiple co-morbidities in the era of a pandemic. Resources for adequate medical care for AI/ANs can be limited due to shortages in Congressional funding, ${ }^{[36]}$ lack of trained medical professionals, medical supplies, and overall staff shortages. A 2018 report by the US Commission on Civil Rights states that AI/ANs receive health care funding support at a rate nearly three times lower than that reported per person nationwide. ${ }^{[37]}$

An analysis of reports received on reservations noted a general lack of health information dissemination in news and community reports. There were issues related to understanding medical terminology and the possibility of fear related to the statements of a new virus similar to those reported in historical events such as small pox and other diseases that caused historical mass devastations. The unavailability of information in the local languages and few translators was of concern. The information was not seen to incorporate local health beliefs and cultural values.

\subsection{Cultural influences}

For indigenous populations, the cultural constructs of health and illness may support or impede the delivery of health education, medical care, tracking and surveillance of COVID-19. Complicating patient-provider relationships and conversations surrounding measures to mitigate and control the spread of illness are: the inability to distinguish between COVID and similar disease symptomology such as bodily pains and discomforts from the flu, common colds or other respiratory ailments; ${ }^{[38]}$ possible fear of reporting movements or travel of individuals, privacy, stigmatization, and limitations in the traditional AI communication styles and preferences for nonverbal communication. ${ }^{[39-41]}$ Both verbal and non-verbal communications are important in exchanges, and differences can lead to not only frustration, but also misunderstandings and misinformation. In addition, differing languages and cultures may create alternate perceptions of etiology or altered illness beliefs, perceived treatment needs for illness, and symptoms of illness. ${ }^{[42]}$ It has been identified that language barriers and literacy levels negatively affect the reception and use of health information. Translation from English to another language has its own difficulties, but to extend the translation into medical and scientific terms or concepts compound the linguistic barrier. Aside from translation issues, educational health and research information should 
provide culturally sensitive information for acceptance and relatability.

The traditional culture of many tribes that emphasizes the interrelatedness of all in nature requires a collaborative ecological approach to mitigate the spread of the virus. Possible culture-bound perspectives and responses to illness create barriers to rapid responses to illnesses, present communication barriers, restrict surveillance, and alter adherence with recommended virus mitigation. ${ }^{[43]}$ Communicable disease education may need thoughtful explanations that include the environment, spread of disease by vectors, and the significance of interrelatedness to facilitate educating community groups to the significance and rapid spread of the disease. Communicating important public health messages may entail the assistance of local AI/AN community health experts, leaders, and respected elders for health messaging and education. Some reservations do not possess rural physical addresses, so the assistance of medical personnel and local community members to help identify homes for contact tracing would be important. More remote communities have concerns about accessing emergency aid due to lack of visibility and inclusion. There is also high movement between the reservation and border towns and urban areas. Due to limited housing and living in close proximity to nuclear and extended family members may result in several adults and children residing in one residence thus impeding social distancing.

For over 500 years, AI/ANs have experienced deadly viruses and other communicable diseases, a history of poverty, low education attainment, and high unemployment. ${ }^{[44]}$ Overcoming these affronts has left a legacy of trauma that include health inequities, exclusion, and disparities in access to healthcare services and environmental injustice.

\section{RECOMMENDATIONS}

American Indian tribes experience inadequate infrastructure in communications, basic living needs (telecommunication, housing, and water), and encounter sociocultural factors that impact their response to health threats such as the COVID-19 pandemic. Their common experiences translate into a high level of risk for infection and multiple co-morbidities in the era of a pandemic.

For indigenous populations, the cultural constructs of health and illness may support or impede the delivery of health education, medical care, tracing and surveillance for COVID19. Complicating patient-provider relationships and conversations surrounding measures to mitigate and control the spread of illness are differences in languages, illness beliefs and cultural values. To address the general lack of public health information flow it is vital to enlist the assistance and support of reputable translation services, local community members, use every-day language and appropriate jargon, and use audiovisual aids that reflect the culture and image of the targeted community. Utilizing local working groups to screen general research information and educational materials is recommended. Local translators or liaisons can be invaluable in their knowledge of the geography, language, customs, community sentiment and other important aspects of community interaction. Enlisting local expertise not only builds capacity and trust, but also engenders community pride and empowerment.

A holistic approach to mitigating COVID-19 is necessary. This approach needs to focus on promoting community benefits and gains in all steps taken to mitigate and control the virus. Individual actions ultimately have an impact on group health. Following the Centers for Disease Control and Prevention/tribal health guidelines, translatable messaging in local languages and cultures, is essential. Adhering to health guidelines as a whole is needed while focusing on the most vulnerable in the community. The elders and those with comorbidities or chronic health conditions such as diabetes and conditions that affect lung, heart, and immune system are at the highest risk categories. Working collectively to check-on and aid the most vulnerable must be a high priority. Providing food, water, other basic necessities, and maintaining open communication with these groups can be done while social distancing and donning a mask. It has been reported that long-term health complications and sequelae are common with COVID-19 infection among those with medical and psychological problems. ${ }^{[45]}$ The economic burden related to COVID complications and disability are anticipated to be high. Addressing the known infrastructure and socio-cultural issues is a significant way to address the short- and long-term consequences of COVID-19.

Vast geography and inadequate location information leaves medical personnel, contact tracers and COVID-19 educators in need of help to identify residential sites for contact tracing, education, and surveillance. More remote communities have concerns about accessing emergency aid due to lack of visibility. There is also a high degree of mobility between the reservation and border towns or cities. Due to limited housing, living in close proximity may result in multigenerational adults and children residing in one residence thus impeding infection control. Communicating important public health messages may entail the assistance of local AI/AN community health experts, leaders, and respected elders for health messaging and education. 


\section{Conclusion}

The recent novel COVID-19 pandemic has highlighted several AI/AN community's infrastructure limitations and cultural factors that are serious barriers to COVID-19 prevention, surveillance and mitigation. Due to infrastructure shortfalls in communication networks, many residents were not notified of COVID-19 in the early stages of the pandemic, thus placing them at risk of contracting the virus. Limited homes with large numbers of family members in residence and the lack of identifiable housing information further restricted notification and surveillance. Many residents were unable to participate in the recommended COVID-19 prevention and control measures such as handwashing, social distancing and mask-wearing. In addition, the ecological beliefs of many tribal groups emphasize the interrelated association with nature - as it is not something to be protected from but instead to live in harmony with - thus the threat of a virus needs to be presented in an ecological approach. The spread and impact of viruses such as COVID-19, will continue to impact tribal communities disproportionately unless the infrastructure that allows for adequate telecommunication, safe water access, increased housing and medical services are addressed within the cultural context of communities.

\section{CONFLICTS OF INTEREST Disclosure}

The authors declare that there is no conflict of interest.

\section{REFERENCES}

[1] Hooper MW, Nápoles AM, Pérez-Stable EJ. COVID-19 and racial/ethnic disparities. JAMA 20 May 11; 323(24): 2466-2467. PMid:32391864 https://doi.org/10.1001/jama.2020.8598

[2] Hatcher SM, Agnew-Brune C, Anderson M, et al. COVID-19 among American Indian and Alaska Native persons - 23 states January 31-July 3, 2020. MMWR Morb Mortal Wkly Rep. 2020 Aug 28; 69: 1166-1169.

[3] Van Dyke ME, Mendoza MCB, Li W, et al. Racial and Ethnic Disparities in COVID-19 Incidence by Age, Sex, and Period Among Persons Aged $<25$ Years - 16 U.S. Jurisdictions, January 1-December 31, 2020. MMWR Morb Mortal Wkly Rep. 2021 Mar 19; 70(11): 382-8. PMid:33735165 https://doi.org/10.15585/mmwr.mm7011e1

[4] CDC. COVID-19 and Your Health: Other People Who Need Extra Precautions [Internet]. Centers for Disease Control and Prevention. 2020 [cited 2021 Mar 24]. Available from: https://www.cdc.gov/coronavirus/2019-ncov/need -extra-precautions/other-at-risk-populations.html

[5] Dewees S, Marks B. Twice Invisible: Understanding Rural Native America [Internet]. Longmont, CO: First Nations Development Institute; 2017. Available from: https://www .usetinc.org/wp - content/uploads/bvenuti/WWS/2017/May\%202017/May\%2 08/Twice\%20Invisible\%20-\%20Research\%20Note.pdf

[6] Bennett-Begaye J, Trahant M, the Associated Press. Five days tells the coronavirus story: caseload jumps from two to 26. Indian Country Today LLC [Internet]. 2020 Mar 22 [cited 2020 May 15]. Available from: https://indiancountrytoday.com/news/fi ve-days-tells-the-coronavirus-story-caseload-jumps -from-two-to-26-vY4nuj3RdUGpbox3eB9PzA

[7] Chappell B. Coronavirus cases spike in Navajo Nation, where water service is often scarce." NPR [Internet]. 2020 Mar 26 [cited 2020 May 15]. Available from: https: //www.npr.org/sections/coronavirus-live-updates /2020/03/26/822037719/coronavirus-cases-spike-in-n avajo-nation-where-water-service-is-often-scarce

[8] Rodriguez-Lonebear D, Barceló NE, Akee R, et al. American Indian reservations and COVID-19: correlates of early infection rates in the pandemic. JPHMP. $2020 \mathrm{Jul} / \mathrm{Aug}$; 26(4): 371-377. PMid:32433389 https://doi.org/10.1097/PHH.0000000000001206

[9] Tuchman G. Navajo Nation has lost more to coronavirus than 13 states: [videocast 3:55 min.]. Cable News Net- work [Internet], 2020 Apr 17. Available from: https: //www.cnn.com/videos/us/2020/04/17/navajo-nativ e-american-coronavirus-pkg-tuchman-ac360-vpx.cnn

[10] Bennett-Begaye J, the Associated Press. Ready or not? Warnings for tribes as COVID-19 epidemic spreads. Indian Country Today LLC [Internet]. 2020 Mar 03 [cited 2020 May 15]. Available from: https://indiancountrytoday.com/news/ready-or-not-w arnings-for-tribes-as-covid-19-epidemic-spreads-c mAgOkyHiOiHmlBtFHIWYA

[11] Coronavirus disease 2019 (COVID-19) update to tribal and urban Indian organization leaders. Indian Health Service [Webinar and teleconference]. 2020 Mar 5. Available from: https://www.ihs.gov/ihscalendar/calendar/coronavir us-disease-2019-covid-19-update-to-tribal-and-urb an-indian-organization-leaders/

[12] Weekend lockdowns, curfews extended. Navajo Times [Internet] 2020 Sept 3 [cited 2020 Sept 30]; Coronavirus Updates. Available from: https://navajotimes.com/coronavirus-updat es/weekend-lockdowns-curfews-extended/

[13] National Congress of American Indians (US). Tribal nations and the United States: an introduction [Internet]. Washington (DC): NCAI; 2020 Feb [cited 2020 May 15]. Available from: http: //www.ncai.org/about-tribes

[14] National Congress of American Indians (US). Demographic profile of Indian country [Internet]. Washington (DC): NCAI; 2012 Nov [cited 2020 May 15]. Available from: https: //www.ncai.org/policy-research-center/research-dat a/II_2012_November_Demographic_Profile_-_Copy.pdf

[15] Federal Communications Commission (US). 2016 Broadband progress report. Washington (DC): FCC (US); 2016 Jan 29. GN Docket 15-191. Available from: https: //www.fcc.gov/reports-research/reports/broadban d-progress-reports/2016-broadband-progress-report

[16] Department of Housing and Urban Development (US). HUD releases comprehensive assessment of housing needs of American Indians and Alaska Natives. HUD Archives [Internet]. 2017 Jan 19 [cited 2020 May 15]; News Releases. Available from: https: //archives.hud.gov/news/2017/pr17-012.cfm

[17] Lovett I, Frosch D, Overberg P. Covid-19 stalks large families in rural America. Wall Street Journal [Internet]. 2020 Jun 7. [cited 2020 Jul 1]. Available from: 
https://www.wsj.com/articles/Covid-19-household s-spread-coronavirus-families-navajo-california-s econd-wave-11591553896? shareToken=st88d807a0fa8340 4080f6766404ad8496\&reflink=article_email_share

[18] Department of Health and Human Services (US), Indian Health Service (US). Fiscal year 2017: justification of estimates for appropriations committees. Rockville (MD): DHHS-IHS; 2017 Mar 26 244p. Available from: https://www.ihs.gov/sites/budg etformulation/themes/responsive2017/documents/FY20 17Congressional Justification.pdf

[19] Sottile C, Ortiz E. Coronavirus hits Indian country hard, exposing in frastructure disparities. NBC Universal News Group [Internet], 2020 Apr 20 [cited 2020 Jul 1]. Available from: https : //www.nbcnews $\mathrm{com} /$ news/us-news/coronavirus-hits-indian-country-h ard-exposing-infrastructure-disparities-n1186976

[20] National Indian Health Board (US). The National Tribal Budget Formulation Workgroup's Recommendations on the Indian Health Service Fiscal Year 2018 Budget: Federal Indian trust responsibility: the quest for equitable and quality Indian healthcare [Internet]. Washington (DC): NIHB; 2016 Jun 21 [cited 2020 Jul 1]. Available from: https://www.nihb.org/docs/06212016/FINAL $\% 20$ FY $\% 2020$ 18\%20IHS $\% 2$ B Budget $\% 20$ Workgroup $\% 20$ Recommendations.pdf

[21] Environmental Protection Agency (US). Navajo Nation: cleaning up abandoned uranium mines - providing safe drinking water in areas with abandoned uranium mines [Internet]. 2020 Oct 13 [cited 2020 Nov 15]. Available from: https://www.epa.gov/navajo-nat ion-uranium-cleanup/providing-safe-drinking-water - areas-abandoned-uranium-mines

[22] Arizona Department of Water Resources (US). Arizona water atlas volume 3 southeastern Arizona planning area. Phoenix (AZ) Arizona Department of Water Resources (US); 2009 Jun. Available from: https://repository . asu.edu/attachments/92786/c ontent/Volume_3_final.pdf

[23] Baker DL, King KA. Environmental contaminant investigation of water quality, sediment and biota of the Upper Gila River Basin Arizona Phoenix (AZ): US Fish and Wildlife Service Region 2; 1994 Jul. Available from: https://azmemory.azlibrary.gov/digital /collection/feddocs/id/319/

[24] Credo J, Torkelson J, Rock T, et al. Quantification of elemental contaminants in unregulated water across western Navajo Nation. Int J Environ Res Public Health. 2019 Jul 31; 16(15): 2727. PMid:31370179 https : //doi .org/10.3390/ijerph16152727

[25] Hoover J, Erdei E, Nash J, et al. A review of metal exposure studies conducted in the rural southwestern and mountain west region of the United States. Curr Environ Health Rep. 2019 Feb 12; 6(34): 34-49. PMid:30906686 https : //doi .org/10.1007/s40471-019-018 2-3

[26] Samuel-Nakamura C, Robbins W, Hodge F. Uranium and associated heavy metals in Ovis aries in a mining impacted area in northwestern New Mexico. Int J Environ Res Public Health. 2017 Jul 28; 14(8): 848. PMid:28788090 https://doi.org/10.3390/ijerph1408 0848

[27] Samuel-Nakamura C, Hodge FS, Sokolow S, et al. Metal(loid)s in Cucurbita pepo in a uranium mining impacted area in northwestern New Mexico, USA. Int J Environ Res Public Health. 2019 Jul 18; 16(14): 2569. PMid:31323819 https://doi.org/10.3390/ijer ph16142569

[28] Samuel-Nakamura C, Hodge FS. Occurrence and risk of metal(loid)s in Thelesperma megapotamicum tea plant. Plants. 2019 Dec 23 9(1): 21. PMid:31877937 https://doi.org/10.3390/plants 9010021
[29] Geological Survey (US), Arizona Department of Water Resources. Geology and ground-water resources of the San Carlos Indian Reservation, Gila, Graham, and Pinal counties, Arizona. Tucson (AZ): USGS; 1989; 89-4152. https://doi .org/10.3133/wri894152

[30] Lewis J, Hoover J, Mackenzie D. Mining and environmental health disparities in Native American communities. Curr Environ Health Rep. 2017 Apr 26; 4(2): 130-141. PMid:28447316 https : //doi. org/10.1007/s40572-017-0140-5

[31] Gibson JM, Pieper KJ. Strategies to improve private-well water quality: a North Carolina perspective. Environ Health Perspect. 2017 Jul 7; 125(7). PMid:28728142 https://doi .org/10.1289/EHP890

[32] Maupin MA, Kenny JF, Hutson SS, et al. Estimated use of water in the United States in 2010. Reston (VA): US Geological Survey; 2014 56 p. Circular 1405.https : //doi.org/10.3133/cir1405

[33] Stoiber T, Temkin A, Andrews D, et al. Applying a cumulative risk framework to drinking water assessment: a commentary. Environ Health. 2019 Apr 30; 18(1). PMid:31036021 https://doi.org/ 10.1186/s12940-019-0475-5

[34] Hodge FS. No Meaningful Apology for American Indian Unethical Research Abuses. Ethics \& Behavior. 2012 Nov; 22(6): 431-44. https ://doi.org/10.1080/10508422.2012.730788

[35] Warne D, Wescott S. Social Determinants of American Indian Nutritional Health. Curr Dev Nutr. 2019 Aug; 3(Suppl 2): 12-8.

[36] Commission on Civil Rights (US). Request for Congressional Appropriation for Fiscal Year 2021. Washington (DC): USCCR; 202033 p.

[37] Commission on Civil Rights (US). Broken promises: continuing federal funding shortfall for Native Americans [Briefing report]. Washington (DC): USCCR; 2018 Dec 314 p.

[38] Givler A, Bhatt H, Maani-Fogelman PA. The importance of cultural competence in pain and palliative care. StatPearls [Internet]. Treasure Island (FL). 2020 Jun 1.

[39] Haozous EM, Knobf MT. "All my tears were gone": suffering and cancer pain in southwest American Indians. J Pain Symptom Manage. 2013 Jun; 45(6): 1050-60. PMid:22940564 https : //doi.org/10.1016/j.jpainsymman.2012.06.001

[40] Heit M. Research summary: Communication styles of Indian peoples. AWASIS J. 1987 Mar [series and volume unknown]. Available from: https://www.lpi.usra.edu/education/lpsc_wksp_2 007/resources/heit_report.pdf

[41] Basso KH. "To Give up on Words": Silence in Western Apache Culture. Southwestern Journal of Anthropology. 1970 Oct 1; 26(3): 213 30. https://doi.org/10.1086/soutjanth.26.3.3629378

[42] Coolen PR. Cultural relevance in end-of-life care. Ethno Med [Internet]. 2012 May 1. [Series and volume unknown]. Available from: https://ethnomed.org/clinical/end-of-life/cult ural-relevance-in-end-of-life-care

[43] Lees YA. Exploring methods of educating Apache children about Rocky Mountain Spotted Fever to reduce outbreaks among adolescents within the tribal environment [Dissertation]. [Minneapolis]: Capella University; 2019. 97 p.

[44] Francis JM. Iberia and the Americas: Culture, Politics, and History (Transatlantic Relations) [Internet]. Santa Barbara, CA: ABC-CLIO; 2005 [cited 2021 Mar 3]. 1165 p. Available from: https://products.abc-clio.com/abc-cliocorpora te/product . aspx?pc=A1502C

[45] Jiang DH, McCoy RG. Planning for the Post-COVID Syndrome: How Payers Can Mitigate Long-Term Complications of the Pandemic. J Gen Intern Med. 2020 Jul 22; 1-4. 